\title{
ABSTRACTS OF THE JOINT MEETING OF THE CLINICAL GENETICS SOCIETY AND THE CLINICAL MOLECULAR GENETICS SOCIETY HELD ON 19 AND 20 APRIL 1990 AT UNIVERSITY OF NEWCASTLE UPON TYNE MEDICAL SCHOOL
}

\author{
Hereditary haemorrhagic \\ telangiectasia: a clinical genetic study \\ M E M PORTEOUS*, J BURN*, \\ $S$ PROCTOR† \\ * Department of Human Genetics, \\ University of Newcastle upon Tyne; \\ tDepartment of Haematology, Royal \\ Victoria Infirmary, Newcastle upon Tyne.
}

Hereditary haemorrhagic telangiectasia (HHT) is an autosomal dominant disorder affecting the vascular wall and characterised by epistaxes and telangiectases. The prevalence has been estimated at 1 in 100000 but our recent prevalence study of HHT in the Northern Region shows this to be an underestimate. HHT is a disorder that seldom presents to the geneticist, most of the care being provided by haematologists and ENT surgeons. We present a 17 year old boy with pulmonary AVM referred for urgent surgical excision resulting in complete resolution of symptoms. HHT is perceived by many medical practitioners as a minor disorder. In our experience this is not the case. Complications in our patients include pulmonary arteriovenous malformations (17\%), gastrointestinal bleeds (16\%), central nervous system complications (13\%), and transfusion dependence $(11 \%)$. We have examined 100 affected and unaffected persons from 16 families with HHT. There are no families showing non-penetrance and we postulate that the gene is almost always expressed. All affected persons in our series had symptoms by the age of $40,85 \%$ showing signs by the age of 25.

\footnotetext{
Cardiovascular abnormalities in the oculoauriculovertebral sequence (Goldenhar syndrome)

P J MORRISON*, N C NEVIN*, B G CRAIG $\dagger$, H C MULHOLLAND $\dagger$ "Department of Medical Genetics, Belfast City Hospital; +Department of
}

\author{
Paediatric Cardiology, Royal Belfast \\ Hospital for Sick Children, Belfast, \\ $N$ Ireland.
}

Oculoauriculovertebral sequence is a heterogeneous disorder characteriséd by defects of the first and second branchial arches, sometimes accompanied by vertebral anomalies and/or ocular anomalies. The diagnostic criteria are poorly defined. Since 1969 , using multiple sources of ascertainment, which included referrals from ENT, ophthalmic, and plastic surgeons, we have identified a total of 25 patients including two male sibs with the condition. Little information is available about the frequency and nature of cardiac defects in this disorder. Twenty-four patients had a cardiovascular examination in which 20 also had electrocardiography (ECG) and echocardiography (ECHO). Of the 20 patients who had ECG and ECHO, 12 had normal cardiovascular findings. Eight patients had a cardiovascular defect: four had isolated ventricular septal defects (VSD), one had VSD and atrial septal defect, one VSD and pulmonary stenosis, one Fallot's tetralogy, and one complex heart defect. The four patients who did not have ECG and ECHO had a normal clinical cardiovascular examination. The patient not personally examined had an apparently normal cardiovascular system. We conclude that some $33 \%$ of patients with oculoauriculovertebral sequence also have a congenital heart abnormality.

\footnotetext{
Mucopolysaccharidosis II (Hunter disease) in a female twin B WINCHESTER, E YOUNG, S GEDDES, S GENET, A HABEL ${ }^{*}$, Y BOYD $\dagger$, $S$ MALCOLM Departments of Clinical Biochemistry and Paediatric Genetics, Institute of Child Health, London WCIN IEH; *West Middlesex University Hospital,
}

\author{
Isleworth, Middlesex; fGenetics \\ Division, MRC Radiobiology Unit, \\ Didcot, Oxon.
}

A 9 year old dysmorphic twin girl suspected of having a mucopolysaccharidosis gave an abnormal urinary GAG pattern consistent with a diagnosis of MPSI (Hurler disease), MPSII (Hunter disease), or a multiple sulphatidosis (MSD). Normal activities of the relevant enzymes excluded MPSI and MSD but a deficiency of iduronate sulphatase was found in plasma and cultured fibroblasts consistent with a diagnosis of Hunter disease. Cytogenetic studies showed a normal $46, \mathrm{XX}$ karyotype. In view of the finding of this $\mathrm{X}$ linked disease in a female, the pattern of $X$ inactivation was studied by determining the methylation pattern of the highly polymorphic DNA locus $27 \beta$. The methylation state of the polymorphic alleles can be determined by digestion with $M s p I$ and the methylation sensitive isoschizomer HpaII. Both fibroblasts and lymphocytes from the patient showed a nonrandom pattern of $\mathrm{X}$ inactivation in contrast to her clinically normal twin.

A genetic study of classical ataxia telangiectasia

C G WOODS, S BUNDEY,

A M R TAYLOR

Departments of Clinical Genetics and Cancer Studies, University of Birmingham, Birmingham.

We studied 47 families from throughout the UK in whom there was at least one living member with ataxia telangiectasia (AT). These families contained 49 index cases ( 26 males and 23 females); 11 out of 79 sibs also had AT, no other relative was affected, and no patient had a child. All but six of the healthy sibs were clinically examined and had radiation studies performed on 
lymphocytic chromosomes. There was no suggestion of increased fetal loss, nor of unexplained childhood deaths, to suggest that further sibs had been affected, nor was there any family limitation after the birth of the index case. The incidence of affected sibs is significantly less than the $25 \%$ expected if all patients had an autosomal recessive condition. A prevalence study conducted in the West Midlands Region found 11 cases in a population of 3600000 people under 50 years of age. In an autosomal recessive disease with this birth incidence $10 \%$ of parental couples would be expected to be consanguineous. There were none found in this study. We suggest that other forms of inheritance account for some cases of ataxia telangiectasia.

$\mathbf{X}$ linked deafness is a heterogeneous disorder

W REARDON*, H MIDDLETON-PRICE*, $S$ MALCOLM*, P PHELPS†, M E PEMBREY*

${ }^{*}$ Mothercare Department of Paediatric Genetics, Institute of Child Health, London WCIN IEH; tDepartment of Radiology, Royal National Throat Nose and Ear Hospital, London WCIX 8DA.

A locus for $\mathrm{X}$ linked deafness with stapes fixation (McKusick No 30440) has previously been assigned to the $\mathrm{Xq13} / \mathrm{Xq} 21$ region based on linkage studies in two large pedigrees (Brunner et al. Hum Genet 1988;80:337-40. Wallis et al. Genomics 1988;3:299-301). Deafness has also been documented among the clinical features of boys who have been shown to have deletions involving this area of the $\mathrm{X}$ chromosome (Cremers et al. Genomics 1989;4: 41-6). We have performed linkage studies in five large pedigrees with $\mathrm{X}$ linked deafness. Our results confirm the previously defined locus with a cumulative lod score of 11.8 using the linked marker X65H7. However, evidence of genetic heterogeneity is provided by one pedigree which shows no linkage to the known locus area. CT scans of the inner ear have confirmed that the deafness in this pedigree is radiologically distinct from other pedigrees with $\mathrm{X}$ linked deafness. We conclude that $\mathbf{X}$ linked deafness is a radiologically and genetically heterogeneous disorder.
Coagulation factor abnormalities in Noonan syndrome

M SHARLAND, M PATTON, A CHITTOLIE, $S$ TALBOT, D BEVAN St George's Hospital Medical School, Cranmer Terrace, London SW17 ORE.

The clinical diagnosis of Noonan syndrome is often difficult in children with a milder phenotype, and in adults where the phenotype has altered with time. A diagnostic marker would aid both diagnosis and counselling. The use of coagulation factor abnormalities as a clinical marker has been studied in 31 subjects (including three families) as part of a large multidisciplinary study. Fourteen out of the 31 had an abnormal bleeding history. This was predominantly increased bruising after trauma or surgery. No major haemorrhagic episodes were reported. The partial thromboplastin time was prolonged in 18/31. The levels of blood factors V, VIII, VWF, VWFag, IX, $\mathrm{XI}$, and XII were measured in all cases. The commonest abnormality was a partial factor XI deficiency in the heterozygote range (21/31). This was a pure factor XI deficiency in 11 patients. In five cases the factor XI deficiency was combined with a factor XII deficiency, in three with a factor VIII deficiency, and in one with a factor IX deficiency. The other abnormalities seen were a combined deficiency of factor V and VIII in two cases, and a pure deficiency of V and VIII in one case. No evidence could be found of a circulating coagulation inhibitor. An abnormal screen was obtained in 23 of 31 subjects $(74 \%)$. In two of the three families studied, the same specific combination of abnormalities was observed in the affected parent and children. It is possible that detailed coagulation factor analysis may be useful in Noonan syndrome as an aid to counselling.

The diagnostic features and natural history of Sotos syndrome

T R P COLE, H E HUGHES

Institute of Medical Genetics, University Hospital of Wales, Cardiff CF4 4XN.

In 1964 Sotos et al described five children with large birth size, advanced bone age, acromegaloid features, and a non-progressive neurological disorder. The non-specificity of these features has led to many false positive diagnoses and a reluctance to make the diagnosis at all. Between January 1989 and 1990 , 79 suspected cases of Sotos syndrome and their families throughout the UK have been assessed. These cases have also been independently reviewed by two other clinical geneticists and there is agreement that $\mathbf{4 0}$ cases fit a 'classical pattern' of Sotos syndrome. The diagnostic features of these particular patients have been looked at critically and their natural history documented. In this group the most significantly increased birth measurement was length (mean +3.2 SD) rather than weight (mean $+1 \cdot 1 \mathrm{SD}$ ). Subsequently, head circumference was consistently raised $(>+2 \mathrm{SD})$, while both height and weight tended to fall towards the population mean. Height often (20/28) was disproportionately increased compared to weight. Ninety-three percent of patients had a bone age advanced to or beyond the 90th centile. However, this incidence appears to be affected by the method, timing, and frequency of assessment. The facial characteristics change markedly with time, gradually becoming longer and the prognathism more pronounced. Developmental and intellectual handicaps were variable. All the children exhibited significant early motor and/or verbal delays and deficits in these areas may render a misleading picture of overall abilities. Follow up into childhood showed that over half the group (19/35) were in normal schools although nine of the 19 required additional help. The extent of morbidity and mortality within the group remains uncertain as only four of the cases were over 18 years old.

\section{Amyoplasia of chest wall in} monozygotic twins (Poland spectrum) J-U WALTHER, IRMGARD FICHTEL Kinderpoliklinik der Universität München.

The concordant occurrence of unilateral hypoplasia of the spinothoracic muscles in monozygotic twin girls is reported. One patient exhibits right sided aplasia of the pectoralis major muscle with concomitant hypoplasia of the nipple and ipsilateral defects of other chest muscles, while the other shows analogous reduction of the dorsal chest muscles on the left with scapular winging. The functional deficit is negligible; skeletal changes are not present in either of the twins. This 
observation raises the issue of pathogenesis. In published reports there is some controversy between a teratogenetic and a genetic interpretation. Some evidence of exogenous damage with subsequent vascular defects supports the former and several pedigrees with familial manifestation point to the latter, thereby suggesting the existence of a clinical Poland 'spectrum'. The concordant but clinically varying manifestation in identical twins could easily be explained as the result of an early disruption of the spinothoracic muscle primordium (linked to the twinning event?) giving rise to a symmetrical distribution of the lesions in the two organisms. In general the opposing pathogenetic data could be reconciled assuming a multifactorial origin with genetic susceptibility and peristatic forces.

\section{Recurrence risks in the offspring of adults born with major heart defects: first results of a British collaborative study \\ J BURN*, R COFFEY†, J LITTLE†, M PEMBREY $\dagger$, J SOMERVILLE $\oint$, N DENNIS\|, B KEETON\|, S HUNTER*, P WALSH*, J LE GASSICKE*, J COLE\|, L BURN*, L ALLAN $\mathbb{\text { II, R ARNOLD }}{ }^{p}$, J DEANFIELD**, M GODMAN†t, C OAKLEY $¥$, O SCOTTSS, J WILKINSON ${ }^{\mathrm{p}}$, N WILSON\$S ${ }^{*}$ Departments of Human Genetics and Cardiology, University of Newcastle upon Tyne; IInstitute of Child Health, London; IIARC, Lyon; $\$ N H H$, London; ||Southampton; ||Guy's, London; ${ }^{P}$ Liverpool; ${ }^{* *}$ GOS, London; HEdinburgh; $¥ \ddagger$ Hammersmith, London; IfLeeds.}

The progressive improvement in surgical intervention for heart malformations has produced a cohort of young adults with major heart defects. For many disorders this is the first generation capable of procreation. Review of surgical records in the major British centres identified 1094 persons born before 1970 who underwent surgery for disturbed situs, abnormal venous, atrioventricular, or ventriculoarterial connection, tetralogy of Fallot, or atrioventricular septal defects. A total of 108 who had died, 31 who lived abroad, and 12 who were known to be mentally retarded were excluded. Of the corrected cohort of 943 cases, 694 (74\%) have been traced and interviewed. In keeping with the majority of studies of less severe defects recurrences were more frequent among the offspring of affected females. Heart defects were identified in $13 / 196$ children of affected mothers $(6 \cdot 6 \%)$ compared to $4 / 179$ children of affected fathers $(2 \cdot 2 \%)(p=0.0341)$. None of the children of affected fathers had other major defects but there were three, two involving genitourinary malformations, among the offspring of females. These differences in offspring recurrence risks may represent the result of imprinting effects.

Autosomal dominant retinitis pigmentosa: evidence for at least two genetic loci

D H LESTER ${ }^{*}$, R BASHIR* ${ }^{*}$, M JAY $\dagger$, A C BIRD†, A F WRIGHT

C F INGLEHEARN*,

S S BHATTACHARYA*

*Department of Human Genetics, University of Newcastle upon Tyne; +Department of Clinical Ophthalmology, Moorfields Eye Hospital, London; $¥ M R C$ Human Genetics Unit, Western General Hospital, Edinburgh.

Recently Dryja et al (Nature 1990; 343: 364 ) observed a mutation in the 23 rd codon of the rhodopsin gene in a proportion of ADRP patients. Linkage analysis with a rhodopsin linked probe C17 (D3S47) was carried out in three large British ADRP families. Significantly positive lod scores ( $\mathrm{Zmax}=$ +5.58 at $\theta=0$ ) were obtained between C17 and one ADRP family. Sequence and oligonucleotide analysis has, however, shown that no point mutation at the 23rd codon exists in affected persons in this family. Significantly negative lod scores were obtained between $\mathrm{C} 17$ and our other two ADRP families (Inglehearn et al, Genomics 1990;6:168, Lester et al, päper submitted). This confirms genetic heterogeneity. Some types of ADRP are caused by different mutations to the rhodopsin or another tightly linked gene at the 3q21-24 locus, while other types of ADRP are the result of lesions elsewhere in the genome.

\section{Autosomal dominant chorea with intellectual preservation and cystic degeneration of the basal ganglia: a differential diagnosis in Huntington's chorea}

J BURN*, D GIBSON*, A CURTIS*, D F ROBERTS*, D I SHEPHERD†, D BATES*

*Division of Human Genetics, University of Newcastle upon Tyne/Neurology and Clinical Genetics, Royal Victoria Infirmary; +Department of Neurology, North Manchester General Hospital.

We present a family with 20 affected members, five still living, in four generations affected by a slowly progressive degenerative disorder. Choreiform involuntary movements have led to the mistaken diagnosis of Huntington's chorea (HC). The clinical distinction is the relative preservation of intellect. CT scan in one case showed an acquired low density area in the basal ganglia. MRI scan in a second showed abnormal signal density in the putamen bilaterally. In both cases similarity to changes seen in Leigh's disease was noted. Neuropathological examination in their 69 year old uncle showed general atrophy with cystic destruction of the lenticular nucleus, anterior limb of internal capsule, and part of the head caudate. Despite this, the diagnosis of $\mathrm{HC}$ was not challenged and members of the younger generation proceeded to assessment for presymptomatic testing. While molecular genetic studies have not, to date, shown any evidence of genotypic heterogeneity it cannot be assumed that this disorder is allelic with HC.

\section{Proposed regulatory role}

of meiotic chromosome pairing for genomic imprinting

M a HULTÉN*, J G hall†

*Regional Cytogenetics Laboratory,

East Birmingham Hospital,

Birmingham B9 5ST;

tDepartment of Medical Genetics, Clinical Genetics Unit (UBC),

University Hospital, Vancouver, BC, Canada V6H $3 N I$.

Genomic imprinting requires a modification of parental chromosome segments in the germ line. We suggest (1) that during parental gametogenesis first meiotic chromosome pairing may play a role as a critical step for modification of the chromatin configuration and condensation, and (2) that this is a heritable characteristic, forming the basis for the mechanisms of differential 
gene expression. This hypothesis is simple and readily testable in experimental systems such as the mouse models involving Robertsonian translocations. EM investigation of the synaptonemal complex is expected to show sex differences in pairing of imprinting chromosome areas.

\section{Three males with structural abnormalities of the $Y$ chromosome N R DENNIS, A COCKWELL, H CLARKE, J CROLLA Wessex Regional Genetic Counselling Service, Southampton General Hospital; Wessex Regional Genetics Laboratory, General Infirmary, Salisbury.}

We report three males with structurally abnormal Y chromosomes; two also had a 45,X cell line detected in blood. (1) A 26 year old man was investigated at the age of 9 because of short stature and undescended testes. His karyotype was $45, \mathrm{X} / 45, \mathrm{X}, \operatorname{dic}(\mathrm{Y})(\mathrm{qter} \rightarrow \mathrm{p}$ ?: $: p ? \rightarrow q$ ter $)$. As an adult he was short and well virilised but had some somatic features of Turner's syndrome. (2) An 11 year old boy was investigated because of short stature and mild learning difficulties. His karyotype was $45, \mathrm{X} / 46, \mathrm{X},+\mathrm{r}$. The ring chromosome was shown by in situ hybridisation to contain Y material. (3) A 6 month old infant was investigated because of failure to thrive and 'soft' dysmorphic features. His karyotype was 46,X,+ mar. The minute marker chromosome was shown by in situ hybridisation to contain $\mathrm{Y}$ material.

\author{
Molecular and cytogenetic studies of \\ ring chromosomes in patients \\ with Turner's syndrome \\ M J MACKENZIE*, P R BETTS†, \\ A E COCKWELL*, J A CROLLA*, \\ D ROBINSON*, S A YOUINGs*, \\ P A JACOBS* \\ ${ }^{*}$ Wessex Regional Genetics \\ Laboratory, Salisbury General \\ Hospital, Wiltshire SP2 7SX; \\ tDepartment of Paediatrics, \\ Southampton General Hospital, \\ Southampton SO9 $4 \mathrm{XY}$.
}

We report the results of a cytogenetic and molecular reinvestigation of a series of 12 patients with Turner's syndrome who were originally reported as 45,X/46,X,r(X) mosaics. Reappraisal showed that in two patients with fairly large ring chromosomes the ring was comprised entirely of $\mathrm{Y}$ material and not $\mathrm{X}$ as originally reported. Because of this unexpected finding we are now reassessing all patients previously reported to have a ring $X$. $X$ linked RFLP studies of the patients and their parents showed the ring $X$ chromosome to be paternal in origin in six patients and maternal in four. This is at variance with the predominantly paternal origin reported for autosomal structural abnormalities.

\section{Molecular and cytogenetic analysis of a familial microdeletion of $\mathbf{X q}$ \\ S WELLS*, D ROBINSON*, S MOULD*, D ROBINSt, P JACOBS* \\ *Wessex Regional Genetics \\ Laboratory, Salisbury General \\ Hospital, Salisbury, Wiltshire \\ SP2 7SX; +South West Surrey \\ Health Authority, St Luke's \\ Hospital, Guildford, Surrey \\ GU1 3NT.}

A male infant was referred for chromosomal analysis because of poor neurological development. He was found to have a deletion in the $\mathrm{Xq}$ arm, his karyotype being 46,Y, $\operatorname{del}(\mathrm{X})(\mathrm{pter} \rightarrow$ q21.1::q21.2 $\rightarrow$ qter). Family studies showed his mother and grandmother to be heterozygous for the same deletion. We attempted to define the deletion molecularly both to provide an accurate prognosis for the proband and unequivocal detection in any future pregnancies. RFLP analysis and $\mathrm{X}$ inactivation studies using differentially methylated DNA probes allow identification of carrier and non-carrier females in this pedigree.

\section{Severe Pallister-Killian}

phenotype associated with neonatal death in an infant with a $47, X X, i(12 p)$ karyotype in $25 \%$ of peripheral lymphocytes

JOHN C S DEAN*, D COUZIN*, G S STEPHEN*, P DUFFTY $\dagger$ * Medical Genetics, Department of Molecular and Cell Biology, University Medical School Buildings, Foresterhill, Aberdeen; +Neonatal Unit, Aberdeen Maternity Hospital, Aberdeen.

After a spontaneous labour at 39 weeks' gestation complicated by fetal bradycardia, a female infant was delivered by forceps and required assisted ventilation for the first 7 minutes of life. Assessment after stabilisation showed typical dysmorphic features of Pallister-Killian mosaic syndrome. Lymphocyte, skin, cord, and chorion fibroblast cultures initiated within the first 12 hours of life showed a $47, \mathrm{XX}, \mathrm{i}(12 \mathrm{p})$ karyotype in $5 / 20$, $14 / 14,0 / 3$, and $0 / 3$ metaphases examined, respectively. The infant remained unresponsive with persistent bradycardia and apnoeic episodes and died at 6 days of life. The high percentage of abnormal lymphocytes may reflect early sampling (there is evidence to suggest that selective loss of the abnormal cell line occurs in haemopoietic tissues (Ward et al. Am $\mathcal{F}$ Med Genet 1988;31:835-9)) or may correlate with the infant's severe phenotype. The absence of abnormal cells in the cord and chorion samples may have resulted from culture difficulties, but the possibility that selective cell loss has occurred from these tissues also may have implications for the reliability of chorionic villus sampling in this disorder.

Should routine specimens for DNA analysis be karyotyped?

$M$ J W FAED, S FORSYTH, M BOXER, A CURTIS, A SHRIMPTON

Department of Pathology and Child

Health, University of Dundee;

Human Genetics Unit, Western General Hospital, Edinburgh.

In Dundee we have adopted a policy of karyotyping the index case from families presenting for DNA analysis. In some cases we have also karyotyped the parents of the index case. There are karyotypes available for 153 molecular genetic specimens. One batch of samples received was shown to be mislabelled by having inappropriate sex chromosomes. All others have had normal male or female karyotypes except for the father of one cystic fibrosis child. This father, without apparent phenotypic abnormality, was found to have only $30 \%$ of cells with a normal male karyotype, the others being female. Despite this, no unusual findings or labelling intensities were observed on RFLPs for chromosome 7 probes. The counselling consequences have to be considered carefully in such circumstances. 
A simple, non-radioactive method for detecting the common Asian Indian $\beta$ thalassaemia mutations J $M$ OLD, $N$ Y VARAWALLA, D J WEATHERALL

National Haemoglobinopathy Reference Service, Institute of Molecular Medicine, Fohn Radcliffe Hospital, Oxford OX3 9DU.

The polymerase chain reaction (PCR) has greatly facilitated the detection of specific $\beta$ thalassaemia mutations by allele specific oligonucleotide hybridisation. However, this approach conventionally uses ${ }^{32} \mathrm{P}$ labelled oligos which is time consuming and hazardous because of the large number of possible mutations. Recently, several alternative techniques have been reported and we have used one of these, the amplification refractory mutation system (ARMS), to develop a quick, non-isotopic method to screen for the Asian Indian $\beta$ thalassaemia mutations. Primers (30mers) which mismatched with the mutation at the $3^{\prime}$ end nucleotide were tested with a common primer and a pair of control primers to find the right conditions for specific priming. Each mutation could be identified by amplification for 25 cycles with an annealing temperature of $65^{\circ} \mathrm{C}$, followed by agarose gel electrophoresis of the product. The technique is very sensitive and is suitable for prenatal diagnosis provided that the fetal DNA sample is absolutely free from maternal contamination.

A technique for the labelling of oligonucleotides with horseradish peroxidase and detection using enhanced chemiluminescence

S J FOWLER, E R HARDING, $M$ R EVANS

Amersham International plc.

A method is described for the labelling of oligonucleotides with horseradish peroxidase (HRP) and subsequent detection using enhanced chemiluminescence (ECL). Oligonucleotides are modified at their $5^{\prime}$ end during automated synthesis using a $\mathrm{C}_{6}$ thiomodifier. These thiolmodified oligonucleotides are then directly labelled with derivatised HRP. After hybridisation, detection of the immobilised oligonucleotide is accomplished using ECL. Results are obtained on film $<5$ hours after starting to label the modified oligonucleotide with HRP. Oligo- nucleotides labelled in this way have been used for several applications including the detection of single base mismatches and screening of colonies and plaques. Stringency is controlled during the washing steps in any one of three ways: by the addition of urea or formamide, or by increasing the temperature. Sensitivities of 25 attomoles are routinely achieved. This technique offers many advantages over other oligonucleotide labelling and detection systems and should prove useful for a wide range of applications.

\section{Polymerase chain reaction} amplification of the $3^{\prime}$ variable region of COL2A1 in a Stickler syndrome family

L M PRIESTLEY*, D KUMAR†, B C SYKES*

*Collagen Genetics Group, University of Oxford, Institute of Molecular Medicine, Fohn Radcliffe Hospital, Oxford OX3 9DU; fCentre for Human Genetics, Langhill, 117 Manchester Road, Sheffield S10 SDN.

Type II collagen is the major structural component of articular cartilage. Its locus COL2Al (12q1.23-3.21) has a number of restriction fragment length dimorphisms which have been useful in family studies of several of the heritable chondrodysplasias (Wordsworth et al. F Med Genet 1988;25:521-7). A 3' variable region has been used in such studies, but with limited success owing to difficulties in distinguishing variable size lengths on traditional Southern blots. This difficulty has been overcome by the use of the polymerase chain reaction to amplify the region such that it may be analysed on polyacrylamide gels, giving bands which appear to vary by one or more repeat unit (31-35bp). We present a Stickler family which had proved to be non-informative at the dimorphic sites. Analysis using PCR, however, generated a lod score of $2 \cdot 86$ at zero recombination in favour of linkage in this family.

\section{Familial defective apolipoprotein B-100: detection and clinical characteristics ALISON DUNNING*, A TYBERG HANSEN*, J GALLAGHER $\dagger$, J VINCENT*,}

R S HOULSTON*, P J TALMUD*, M SEED*, A HAMSTEN ${ }^{*}, \mathrm{~N}$ MYANT $†$, $S$ E HUMPHRIES*

${ }^{*}$ CXSRC, Lurgan Avenue, London W6 8LW; +MRC Lipoprotein Team, Hammersmith Hospital, London; $\ddagger$ Karolinska Institute, Stockholm, Sweden.

Recently, workers in the US reported a mutation in the ApoB gene that causes familial defective ApoB100 (FDB). This dominantly inherited disorder leads to increased serum concentration of low density lipoprotein (LDL) cholesterol with reduced affinity of the LDL for the LDL receptor. The causative mutation is a $G$ to A base change in exon 26 of the ApoB gene, which creates an amino acid substitution of glutamine for arginine at residue 3500 of the mature protein. This mutation can easily be detected using PCR and oligo melting. We have screened over 1000 subjects with hyperlipidaemia and atherosclerosis and have identified 10 patients with this mutation. All patients had a family history of atherosclerosis. Many of the patients had a clinical diagnosis of familial hypercholesterolaemia (FH) and in our study $3 \%$ of patients with a diagnosis of FH have had this defect. Although rare, it would be technically very easy to screen at risk subjects at birth for this mutation using DNA extracted from Guthrie blood spots.

A case of $\alpha$ thalassaemia caused by chromosome truncation A O M WILKIE*, J LAMB*, P C HARRIS*, R D FINNEY†, D R HIGGs* *MRC Molecular Haematology Unit, Institute of Molecular Medicine, Fohn Radcliffe Hospital, Headington, Oxford OX3 9DU; +Department of Haematology, North Tees General Hospital, Stockton-on-Tees, Cleveland.

A man originating from the northeast of England presented with haemoglobin $\mathbf{H}$ disease. His $\alpha$ globin genotype was $-\alpha / \alpha \alpha$, and his mother, who had the phenotype of $\alpha$ thalassaemia trait, was $\alpha \alpha / \alpha \alpha$. This suggested that both family members carry an $\alpha$ globin allele which is inactivated, but not deleted; neither has any other clinical abnormalities. Further investigation by 
analysis of informative polymorphism and gene dosage showed a deletion starting $60 \mathrm{~kb}$ upstream of the $\alpha$ globin locus and extending away from it. To our surprise, we were unable to detect any breakpoint fragments using probes proximal to the break; however, further analysis showed a distinct smear of hybridisation 1 to $10 \mathrm{~kb}$ distal to the breakpoint, suggesting that the sequence beyond is variable in length and probably telomeric. We have confirmed this by Bal 31 exonuclease digestion, and demonstrated specific amplification of this region using a primer complementary to the canonical human telomeric sequence(TTAGGG) together with a primer just proximal to the breakpoint. The sequence across the breakpoint is identical in the mother and the son, and shows that ('TTAGGG) has been added directly to the site of the break. Our findings have important implications for understanding the processes involved in chromosome truncation, suggesting that a telomerase activity has the capacity to 'heal' broker. ends and that the added (TTAGGG) repeat is alone sufficient to stabilise the new end. In addition, the absence of mental handicap in this family excludes involvement of sequences distal to $\alpha$ globin in causing the deletion type of $\alpha$ thalassaemia/mental retardation syndrome. The $\alpha$ thalassaemia phenotype associated with this mutation may result from deletion of cis acting regulatory sequences lying upstream of the $\alpha$ globin complex.

\section{Identification of genetic} determinants of blood pressure H R DAVIDSON*, G C M WATT $\dagger$, $S$ B HARRAP $\ddagger$ J M CONNOR* *Duncan Guthrie Institute of Medical Genetics, Yorkhill, Glasgow; +Department of Community Medicine, University of Glasgow; $¥ M R C$ Blood Pressure Unit, Western Infirmary, Glasgow.

Human twin and animal breeding studies have shown that blood pressure is inherited as a multifactorial trait with an estimated genetic contribution of $\mathbf{3 0}$ to $60 \%$ of the variance. The Ladywell Family Blood Pressure Study was designed to identify the primary genetic determinants of blood pressure and involved identifying the offspring of adults whose blood pressures had been measured as part of the MRC study into mild hypertension. The offspring were divided into four groups depending on their own and their parents' blood pressure measurements, allowing comparison of persons with contrasting predispositions to developing high blood pressure. These 200 offspring have had extensive biochemical characterisation and their DNA has been analysed for RFLPs at candidate gene loci including the glucocorticoid receptor, atrial natriuretic peptide, and renin. High blood pressure was associated with significantly raised levels of angiotensinogen $(\mathrm{p}<0.01)$, cortisol $(\mathrm{p}<0.02)$, and 18$\mathrm{OH}$ corticosterone $(\mathrm{p}<0.02)$ in offspring whose parents have high blood pressure. This group of offspring also had a higher proportion of homozygotes for the larger allele detected by $B c l I / G R L$, suggesting this locus may be involved in predisposition to hypertension, whereas the RFLPs for renin and ANP were distributed equally throughout the four groups. This approach should permit the resolution of primary and intermediate determinants of blood pressure and could be applied to other human multifactorial traits.

\section{TGF-beta genes in palate}

development

DAVID R FITZPATRICK, ROSEMARY J AKHURST, J M CONNOR

Duncan Guthrie Institute, Yorkhill, Glasgow.

There are currently five members of the transforming growth factor type beta (TGF-beta) gene family, three of which have been cloned in mouse and man. We have used in situ hybridisation to study expression patterns of these complex regulators of cellular function in murine palatogenesis. TGF-beta3 has the most striking expression pattern with hybridisation to the epithelia of the vertical palatal shelves and to the epithelia of the nasal septum that will go on to fuse with the palate. Expression continues in the medial edge epithelia (MEE) of the horizontal palatal shelf and epithelial seam of the fusing shelves with loss of hybridisation as the seam disrupts. TGF-betal expression starts later than beta3 but follows a similar epithelial pattern from the horizontal palatal shelf stage. The timing of TGF-beta2 expression is similar to TGF-betal but is situated in the mesenchyme underlying the MEE rather than epithelially. These data argue an important role for TGF-beta isoforms in mammalian palatogenesis.

Screening for neural tube defects in high risk families using ultrasound alone

LYN S CHITTY, S CAMPBEI.L

Department of Obstetrics and

Gynaecology, King's College Hospital, London.

Traditionally, screening of women at increased risk of carrying a fetus with a neural tube defect (NTD) because of a positive family history has been a combination of ultrasound examination and amniotic fluid $\alpha$ fetoprotein (AF-AFP) and/or acetylcholinesterase measurement. At King's College Hospital amniocentesis has been abandoned in favour of expert ultrasound examination. The efficacy of this policy has been assessed. We have reviewed the pregnancy outcome for all women with a positive history for a NTD who were scanned in the last three years in the ultrasound department at King's College Hospital. The records at $\mathrm{KCH}$ were inspected and where the outcome was unknown the referring hospital was contacted. A total of 490 fetuses was scanned. There were 12 recurrences and seven other: abnormalities detected. The outcome has been confirmed in 467 pregnancies (95\%), replies are awaited in 17 cases, and six have been lost to follow up. There have been no false negative or false positive results. These results support the view that women at increased risk of a pregnancy complicated by a NTD should not have AF-AFP estimation but should only have detailed ultrasound examination, thus avoiding the risk and trauma of amniocentesis.

Total intragenic recombination frequency for the Duchenne/Becker muscular dystrophy gene

STEPHEN ABBS, ROLAND G ROBERTS, CHRISTOPHER MATHEW,

DAVID R BENTLEY, MARTIN BOBROW Paediatric Research Unit, Division of Medical and Molecular Genetics, United Medical and Dental Schools, Guy's Hospital, London SE1 9RT.

The error rate of any RFLP based risk calculation or prenatal diagnosis is highly dependent upon recombination frequencies between the disease and marker loci used. For approximately 
$40 \%$ of Duchenne and Becker muscular dystrophy families in which the mutation cannot be identified, linkage analysis is widely practised. However, the majority of intragenic recombination frequencies incorporated into Bayesian type calculations are generally unknown. In order to ascertain, for the first time, an estimate of the total frequency of recombination across the dystrophin gene, we have typed the CEPH panel of normal families with two new polymorphisms (discovered in our laboratory) which are located at the two extremities of the gene. Multipoint linkage analysis suggested a total recombination of approximately $12 \%$ across the $2 \mathrm{Mb}$ gene, approximately five times greater than the average genetic distance of $1.2 \mathrm{cM}$ per $\mathrm{Mb}$ reported over the whole of the $X$ chromosome (Drayna and White, 1985). The high frequency is compatible with previous reports of $5 \%$ recombination between intragenic polymorphic loci and DMD mutations which are heterogeneous in location. Our study also shows that this high frequency of recombination is not limited to DMD/ BMD families, as has been suggested in the past.

\section{Preliminary experience with linked probes in the presymptomatic diagnosis of FAP \\ F MACDONALD*, M RINDL*, C McKEOWN†, J HAYDON†, M KEIGHLEY‡, J GIBSON§, M HULTEN* \\ *DNA Laboratory, Regional Genetics Service, tClinical \\ Genetics, $\$$ Department of \\ Ophthalmology, East Birmingham \\ Hospital, Birmingham; \\ $\mp$ Department of Surgery, Queen \\ Elizabeth Hospital, Birmingham.}

Familial adenomatous polyposis (FAP) is an autosomal dominant disorder characterised by the presence of hundreds of polyps throughout the colon. At least one of these polyps develops into an adenocarcinoma from the second decade of life onwards. Persons at risk are therefore screened by regular sigmoidoscopy from the mid teens onwards. Closely linked DNA markers on chromosome 5 flanking the disease locus have been identified for use in presymptomatic diagnosis. Forty-two families with FAP have so far been notified to the West Midlands FAP register. These families contain
51 affected and 107 subjects at risk. Sixty-four percent of affected subjects in the 11 families tested so far were informative with at least one of the probes used, Pi227 and YN5.48 being the most informative and C11pll the least. DNA results could be used to reduce the risk in 16 of the 21 at risk subjects and again the most informative probe was Pi227. Only two of the 16 were informative with flanking markers. One recombinant was identified, the recombination occurring between C1lpll and the apc gene. Several problems were identified in the families, including uncertain diagnosis and unsuitable family structure which limited the use of DNA probes. In practice, therefore, only six out of the 11 families were fully informative.

\section{The haplotype distribution of} the $\triangle$ F508 mutation in Scotland I McINTOSH, A CURTIS, M-L LORENZO, A E SHRIMPTON, C T JONES, M KESTON, D J H BROCK Human Genetics Unit, University of Edinburgh, Western General Hospital, Edinburgh EH4 2XU.

The recent isolation and sequencing of the gene responsible for $\mathrm{CF}$ has led to the identification of a 3 bp deletion resulting in the loss of a phenylalanine residue from position 508 of the mature protein $(\triangle F 508)$. It has been shown that $68 \%$ of the disease alleles can be attributed to this small deletion in the Canadian population and the remainder comprise a heterogeneous group of as yet uncharacterised mutations. We have carried out an extensive study of CF families in Scotland (mostly of Celtic and Anglo-Saxon origin) in an attempt to determine the likely heterogeneity of the CF mutations using both haplotype and $\Delta$ F508 deletion analysis. We found $\Delta F 508$ to be present on approximately $75 \%$ of CF chromosomes and in linkage disequilibrium with the $2 \cdot 1 / 6 \cdot 6$ (XV2c, KM19) haplotype. The previously observed disequilibrium between this haplotype and CF mutations is not solely the result of the deletion.

Combined haplotype and mutation analysis in a sample of English cystic fibrosis patients

CAROLYN WILLIAMS, EILA WATSON, EDWARD MAYALL

North West Thames Regional DNA Lab,
Department of Molecular Genetics, St Mary's Hospital Medical School, London W2 $1 P G$.

The frequency of the most common mutation causing cystic fibrosis, $\Delta F 508$, was found to occur with a frequency of $80 \%$ in a population of 252 British CF chromosomes. It was also shown that over $95 \%$ of these chromosomes were of the B haplotype (KM19:2, XV2c:1). $A$ joint analysis of data from seven British DNA laboratories has been undertaken, analysing 884 CF chromosomes for $\Delta F 508$ typings and associated KM19, XV2c haplotypes. Overall, the frequency of $\triangle F 508$ among CF chromosomes from this data set was found to be $78 \% ; 87 \%$ of all $\mathrm{CF}$ chromosomes were of haplotype $B$ and $55 \%$ of non- $\Delta$ F 508 chromosomes were also haplotype ' $B$, compared to only $13 \%$ of normal chromosomes. Bayes' theorem has been applied to the combined data set in order to calculate the carrier risk of an unknown chromosome with a particular haplotype and more accurate carrier risk estimates for subjects with a particular genotype who do not carry $\Delta F 508$ and have no family history of the disorder. We have clinical information on $75 \mathrm{CF}$ patients and have looked for any association between genotype and phenotype. Heterozygotes for $\Delta$ F508 with an as yet undefined mutation appear to fall into at least two different categories. One category cannot be distinguished from $\Delta$ F508 homozygotes and the other appears to be associated with a milder clinical picture. None of the CF-PS subjects (four to date) we have studied is homozygous for $\Delta \mathrm{F} 508$. Meconium ileus does however appear to be associated with homozygosity for $\Delta F 508$. Those subjects lacking a $\Delta$ F508 mutation also appear to fit into both mild and severe categories.

\section{A problem CF family}

A E SHRIMPTON*, J C S DEAN†, A CURTIs*, $\mathrm{K}$ ROss†

${ }^{*}$ Human Genetics Unit, University of Edinburgh, Western General Hospital, Edinburgh; + Medical Genetics, Department of Molecular and Cell Biology, Aberdeen University Medical School, Aberdeen.

A Scottish family with a CF child were scored for nine diallelic CF linked markers. The uncle of the proband married a known CF carrier and this 
couple received prenatal diagnosis since studies of the extended pedigree using KM19/PstI, XV2c/TaqI, and $\mathrm{pJ} 3.11 / \mathrm{MspI}$ indicated that he was also a carrier. Subsequent re-evaluation showed that while the proband was homozygous for the $\Delta \mathrm{F} 508$ deletion, his 'father' was not a carrier. Marker haplotypes rendered uniparental disomy unlikely, and a sequence alteration in the PCR primers or ASO target was eliminated. Seven of the nine diallelic markers previously scored indicated an approximately $11 \%$ chance of a random subject having the appropriate paternal genotype. Nevertheless, analysis using Jeffries' $33 \cdot 15 /$ HinfI multiallelic marker system indicated non-paternity. Fortunately, this is the only CF family out of 98 so far re-evaluated in which deletion/mutation studies have shown non-paternity. The family emphasises the poverty of paternity information generated by diallelic marker systems, and the need to counsel families carefully regarding non-paternity if inappropriate prenatal tests are to be avoided.

Anxiety and depression after predictive testing for Huntington's disease

D CRAUFURD, A DODGE,

L KERZIN-STORRAR, A KHAN,

R HARRIS

Department of Medical Genetics, St Mary's Hospital, Manchester.

Following the identification of linkage markers for Huntington's disease, several regional genetic centres have started to offer predictive testing to persons at risk. This has led to concern about the psychological impact of such tests on those given an unfavourable prediction. We have carried out detailed psychological assessments of persons having predictive tests and report here the results of follow up to date. Forty patients have been given results; four more were uninformative. There were 25 favourable and 14 unfavourable results, while one person was initially given a high risk which was later reduced. Thirty seven have been followed up for at least three months, and 24 for six months. Measures of depression, hopelessness, and neuroticism rose to a peak after three months in those with unfavourable results but remained constant in those with low risks. Anxiety levels were significantly greater in high risk subjects before results were given and remained high in this group, while declining in those given a low risk. More than half of the high risk group experienced distressing symptoms such as insomnia, while two required antidepressant medication or psychotherapy. One self-poisoning incident occurred. We conclude that presymptomatic testing should be offered only after careful counselling and with adequate arrangements for follow up and support.

Ethical issues and predictive testing for Huntington's disease MICHAEL MORRIS, AUDREY TYLER Institute of Medical Genetics, University of Wales College of Medicine, Cardiff CF4 $4 X N$.

In January 1990, the 'Ethical issues policy statement on Huntington's disease molecular genetics predictive test' was published $(\mathcal{F}$ Med Genet and $\mathcal{F}$ Neurol Sci). This document, which was prepared by a joint committee of the World Federation of Neurology and the International Huntington Association, offers guidelines for good practice in predictive testing for $\mathrm{HD}$. The WFN and the IHA have invited debate on these guidelines. The experience in south Wales with nearly 300 applicants for predictive testing, while supporting the need for such a policy statement, has also shown that further discussion and clarification is necessary. In particular discussion will examine inclusion criteria for the test, whether a prenatal test should be offered to an applicant who has had an adverse presymptomatic result, the legal ownership of DNA samples, and non-paternity. Other ethical issues which were not covered by the guidelines have also arisen (for example, the use of anonymous testing and whether the test should be used in the clinical investigation of a patient with atypical symptoms). A multidisciplinary debate should be of value in future revisions of the Policy Statement.

\section{Spondyloepiphyseal dysplasia: phenotypic, genetic, and molecular heterogeneity \\ P BEIGHTON, R RAMESAR, C SHER, P TSIPOURAS \\ $M R C$ Research Unit for Inherited Skeletal Disorders, University of Cape Town, South Africa.}

The spondyloepiphyseal dysplasias (SED) are a group of heritable bone disorders with predominant involvement of the vertebral bodies and epiphyses of the tubular bones Previous researchers have established that the type II collagen gene (COL2Al) is linked to the phenotype in some families with autosomal dominant SED congenita. In addition to the classical congenita form of SED, atypical variants are sometimes encountered. This latter category is represented in South Africa by large families with Namaqualand hip dysplasia (NED), SED type Kimberley (SEDK), Upington bone disease (UBD), and Beukes hip dysplasia (BHD). In these conditions, which are all inherited as $\mathrm{AD}$ traits, the major changes are in the femoral heads and the spine and they can therefore be broadly classified as SED. These conditions are all ostensibly private syndromes and although they differ phenotypically, it is possible that some of them share the same fundamental gene defect. In order to investigate syndromic status and possible genetic heterogeneity, molecular linkage studies involving COL2Al have been undertaken. We have established linkage between $N H D$ and $C O L 2 A I O$ (lod 4.2) whereas $S E D K$ and $C O L 2 A I$ are not linked, thus demonstrating genetic heterogeneity.

\section{Assignment of Waardenburg syndrome type 1 to $2 \mathrm{q} 37$}

A P READ*, C FOY*, V E NEWTON†, R HARRIS*

*Department of Medical Genetics and fCentre for Audiology,

Manchester University.

Waardenburg syndrome type 1 (WS1, McKusick 19350) is an autosomal dominant syndrome of sensorineural deafness, pigmentary disturbances (heterochromia iridis, white skin patches, white forelock), and mild facial dysmorphology (dystopia canthorum, broad nasal root). In animals the combination of deafness and white spotting is caused by defective migration of melanocytes from the neural crest. After excluding $23 \%$ of the genome in a linkage study, we obtained a lod score of 4.76 at a recombination fraction of 0.023 between $W S 1$ and the placental alkaline phosphatase gene $A L P P$. ALPP has been mapped to $2 \mathrm{q} 37$. This location was suggested by 
a report of a Japanese child with de novo WS1 and a de novo inversion of $2 q 35-q 37$. Distal $2 q$ is homologous to proximal chromosome 1 of the mouse, where there is a mutation Splotch. Splotch heterozygotes have white spotting; homozygotes have inner ear malformations and severe neural tube defects. We suggest that WS1 may be the human homologue of Splotch. One large family with type 2 Waardenburg syndrome showed no linkage to $A L P P$, showing that Waardenburg syndrome is heterogeneous genetically as well as clinically.

\section{Gene mapping studies in}

Von Hippel-Lindau disease

E R MAHER*, E BENTLEY*,

J R W YATES*, D BARTON*,

A JENNINGS†, I FELLOWS $\ddagger$,

M A PONDER*, B A J PONDER*,

C BENJAMIN $\oint$, R HARRIS $\oint$,

S BUNDEY \|, M A FERGUSON-SMITH*

*Cambridge University

Department of Pathology.

tHallamshire Hospital,

Sheffield; $¥$ University Hospital,

Nottingham; \$Department of

Medical Genetics, University of

Manchester; ||Department of

Medical Genetics, Birmingham.

Genetic linkage studies were performed in 18 families (140 subjects, 72 affected patients) with von Hippel-Lindau disease using RFLPs at three loci (DNF1582, THRB, $R A F I)$ on the short arm of chromosome 3. Significant linkage was detected between $V H L$ disease locus and $R A F 1$ ( $Z \max =4.45$ at $\theta=$ 0.06 , confidence interval $0 \cdot 01-0 \cdot 19$ ). Multipoint linkage analysis suggested that the most likely location for the VHL disease locus is telomeric to THRB. These results confirm that a gene for VHL disease is localised on the short arm of chromosome 3. Formal heterogeneity testing with the HOMOG program provided no evidence for genetic heterogeneity in VHL disease.

\section{Posters}

Genetic disease in a paediatric ITU DAVID R FITZPATRICK

Duncan Guthrie Institute of Medical Genetics, Royal Hospital for Sick Children, Yorkhill, Glasgow.

A retrospective survey of 823 con- secutive admissions to a combined general paediatric and paediatric cardiothoracic ITU was carried out in an attempt to quantify the 'load' of genetic disease. Of all admissions, $5.7 \%$ had clearly genetic disease, $47 \cdot 7 \%$ had multifactorial conditions, $4 \cdot 1 \%$ had developmental anomalies, $10.4 \%$ had familial disorders, and $30 \cdot 2 \%$ had non-genetic disease. Patients with a clearly genetic disease had an average stay of 8.6 days compared with 3.5 days for nongenetic (NG) conditions and $4 \cdot 2$ days for the whole group (WG). They also had a greater number of readmissions $(23.4 \%)$ than NG $(4.4 \%)$ and WG (10.5\%). More importantly, the genetic group accounted for $22 \cdot 2 \%$ of deaths in the survey compared with $8 \%$ for NG and $8.8 \%$ for WG. Genetic disease therefore constitutes a significant load on ITU both in terms of mortality and morbidity, suggesting a role for the clinical geneticist in this area.

\section{The North Western}

Neurofibromatosis Register: clinical and molecular aspects

A COLLEY*, P COLLEY*,

C BENJAMIN*, T STRACHAN*, M SUPER†, D DONNAI*, R HARRIS*

${ }^{*}$ Regional Clinical and

Molecular Genetic Service,

St Mary's Hospital; +Clinical

Genetics Unit, Royal Manchester

Children's Hospital, Manchester.

In 1989 neurofibromatosis (NF) was added to the long established Genetics Family Register based in the Regional Genetics Service at St Mary's Hospital, Manchester. The prime purpose of the register service is to enable genetic counselling to be offered to all who can benefit from it, to ensure the appropriate storage of DNA and other samples for future family needs, and to facilitate laboratory work in the areas of service and research. Annual review, ongoing support, and the application of new techniques are integral parts of this approach. Ascertainment of subjects and families with NF-I has been through genetic, paediatric, neurology, and dermatology clinics and 90 kindreds have been registered with 205 affected subjects in the North West Region. A NF-I clinic has been established at both SMH and RMCH. Clinical features are documented and we are particularly interested in unusual types of NF-I, for example, segmental, NF-I/Noonan, and other syndromes with café au lait patches. The gene defect causing NF-I has been mapped to chromosome $17 \mathrm{q}$ by linkage analysis. We have carried out molecular studies on over 20 families using two probes which map between translocation breakpoints associated with NF-Iprobe NFCI -4 and pEHI (Dr F Collins, Mich, USA). Probe pEHI detects an EcoRI polymorphism which has been useful in two NF-I/Noonan syndrome families. NF-I, with its variability and unpredictability, brings psychological stress and social burden. A two year research project, designed by the NF Genetic Associate, aims to ascertain patients' knowledge of NF, how their personal experiences relate to their perception of NF and their reproductive options, and to identify the extent of the psychosocial problems caused by NF-I. It is hoped that this research will highlight the needs of NF families so that we can improve our service.

Autosomal dominant

macrocephaly: benign familial macrocephaly or a new syndrome?

T R P COLE, H E HUGHES

Institute of Medical Genetics,

University Hospital of Wales, Cardiff.

During a national study of 79 suspected cases of Sotos syndrome, six patients were identified who failed to fit the phenotype of this condition, but who showed remarkable similarities to each other. The features noted in the probands were: a progressive megalencephaly resulting in an OFC greater than $+3.5 \mathrm{SD}$, normal or near normal birth weights and lengths but an accelerated postnatal increase in weight leading to obesity in four cases, variable developmental delay, and typical facies. The latter was characterised by a square outline with a dished out midface, biparietal narrowing, and a long philtrum. Bone ages (TW2 assessments) were available in four cases and all were under the 75th centile. Two were below the 10th centile and a third case was delayed between the 10th and 25th centiles. Investigation of the probands' families showed a further 13 relatives with features suggestive of the same condition inherited in an autosomal dominant fashion. Although these cases could represent one end of the 
spectrum of benign familial macrocephaly (BFM), they appear to differ from this diagnosis in the frequency and severity of developmental delay (four cases IQ <70) and the facial characteristics which have not been documented in previous descriptions of BFM.

\section{Chromosome anomalies in spontaneous miscarriages \\ H R DAVIDSON, J L TOLMIE, J PATERSON \\ Duncan Guthrie Institute of Medical Genetics, Yorkhill, Glasgow.}

We looked at chromosome results and necropsy reports on all fetuses resulting from spontaneous miscarriages seen in our department during 1982. At this time there was a policy of unselective chromosome analysis. There were 370 fetuses received during this 12 month period; $18 \%$ could not be set up but of those that were, $85 \%$ gave a result. The rate of cytogenetic abnormality was $2.9 \%$ in phenotypically normal fetuses, $3 \cdot 5 \%$ in macerated but otherwise normal fetuses, $86 \%$ in abnormal fetuses of less than 12 weeks' gestation, and $42 \%$ in abnormal fetuses after 12 weeks. Trisomy 21 was found in a macerated 'normal' fetus, but other cytogenetic abnormalities in normal fetuses beyond 12 weeks all involved the sex chromosomes. Two unbalanced translocations were discovered among the phenotypically abnormal fetuses. One was de novo and the other was in a family already known to the department. Thus, with limited resources, cytogenetic analysis might be better concentrated on those fetuses who are abnormal on pathological examination.

\section{Ring chromosome 6 in mother and daughter \\ H R DAVIDSON, A COOKE, J COLGAN, J L TOLMIE \\ Duncan Guthrie Institute of Medical Genetics, Yorkhill, Glasgow.}

A patient with ring chromosome 6 is described. She had severe growth retardation without other major abnormalities, and died suddenly at the age of 3 from meningococcal septicaemia. The ring chromosome was inherited from the patient's mother, who also had proportionate short stature. Conventional cytogenetic examination and flow cytometry were unable to detect any difference in size between the ring chromosome and its normal homologue. This is consistent with the suggestion that the 'ring syndrome' of growth retardation and minor dysmorphisms results from the presence of the ring itself rather than any associated loss of chromosome material.

Insertional translocations

R DAVIDSON, E BOYD, R MURRAY, J COLGAN, I BOYD

Duncan Guthrie Institute of Medical Genetics, Yorkhill, Glasgow.

Insertional translocations are said to occur at a frequency of 1 in 5000 . We have looked at data from our own laboratory since 1965 and have found four families with an insertional translocation, all ascertained via a handicapped child. Comparison with other translocations ascertained during the same period would suggest a much lower frequency, closer to 1 in 25000 . The risk of a liveborn handicapped child is close to the theoretical risk of $50 \%$. In the four families, there was a total of eight subjects with an unbalanced karyotype, all handicapped, and one fetus who was terminated with a similar abnormality as his handicapped aunt. In one family, two cousins were trisomic and another monosomic for the same portion of chromosome lq with contrasting clinical features. A review of published reports confirms the rarity of these aberrations ( 56 reports), the high risk of a handicapped child, and their value in demonstrating the features of 'pure' trisomy and monosomy for the chromosome segments involved.

\section{Two new cases of 21q- 'syndrome' D R FITZPATRICK, H R DAVIDSON, A COOKE, A DUNLOP Duncan Guthrie Institute of Medical Genetics, Yorkhill, Glasgow.}

We describe two patients with deletion of the distal long arm of chromosome 21. The first is mosaic for this abnormality with $40 \%$ of his blood cells having a normal male karyotype. $\mathrm{He}$ is, however, severely growth retarded, dysmorphic, mentally retarded, and blind. The second case has a nonmosaic deletion but has only mild dysmorphic features and mild to moderate mẹntal retardation. Their deletions are similar by conventional cytogenetics and flow analysis. There have been several previous reports of similar deletions but none in mosaic form.

Variable simple sequence elements in the prenatal diagnosis of myotonic dystrophy

N FAIRWEATHER*, K F KELLY*, N SMITH†, C CLARK*, T BROWN*, N E HAITES ${ }^{*}$

${ }^{*}$ Medical Genetics, Department of Molecular and Cell Biology, tDepartment of Obstetrics and Gynaecology, University of Aberdeen, Medical School, Aberdeen.

The polymerase chain reaction (PCR) has been used to detect an abundant class of short repeat DNA families of the form $(\mathrm{dC}-\mathrm{dA}) \mathbf{n}$. (dG-dT)n, known as microsatellites (Weber and May. Am $\mathcal{F}$ Hum Genet 1989;44:388-96). These units are found throughout the human genome and have been characterised for several loci including APO C2 on chromosome $19 \mathrm{ql2}-\mathrm{q} 13.2$. The locus APO C2 is closely linked to the gene for dystrophia myotonica and it is possible to use the informative microsatellite region (11 alleles, PIC 0.79) (HGM10) to predict the risk of inheriting the gene for dystrophia myotonica. A mother presented at the antenatal clinic at 15 weeks' gestation. She was primigravida and 38 years of age. Blood was obtained from the fetus's father and chorion villus sampling was performed by one of us (NS) at $151 / 2$ weeks' gestation by ultrasound. After DNA extraction from the CVS material and parental blood samples, microsatellite analysis was carried out by the polymerase chain reaction. Analysis of the PCR products on a denaturing acrylamide sequencing gel indicated that the fetus was not affected, a result confirmed by Southern analysis with the probe APO C2 (Meredith et al. Br Med $\mathcal{F}$ 1987;293:1353-6). The PCR result was produced in three days compared to eight days for the Southern technique.

PCR sequencing of the HLA-B55 associated CYP21B allele which causes 21-hydroxylase deficiency SIMON COLLIER, PAUL J SINNOTT, RODNEY HARRIS, TOM STRACHAN 
Department of Medical Genetics, St Mary's Hospital, Manchester.

The extended HLA haplotype A11, B55, DR4, C4A4, C4B6, appears to be the most common 21-hydroxylase haplotype in the British population, which is associated with a point mutation in CYP21B rather than a large scale deletion (Collier et al. EMBO $\mathcal{F}$ 1989;8:1393-402). A CYP21B deletion heterozygote who carries this haplotype has been used to analyse the $\mathrm{B} 55$ related CYP21B mutant allele by PCR sequencing. Sequence analysis suggests that this CYP21B allele has undergone multiple gene conversion-like events which have introduced CYP21A pseudogene specific sequence at the CYP21B locus. One of these changes, a $\mathrm{T} \rightarrow \mathrm{A}$ transversion in exon 4 , produces an Ile to Asn change which has been previously suggested to be pathological (Amor et al. Proc Natl Acad Sci USA 1988;85: 1600-4).

\section{Prenatal diagnosis in osteogenesis imperfecta \\ J R LYNCH, D J OGILVIE, \\ L M PRIESTLEY, C M BAIGRIE, \\ B C SYKES \\ Collagen Genetics Group, University of Oxford, Institute of Molecular \\ Medicine, Fohn Radcliffe Hospital, Oxford.}

Dominantly inherited osteogenesis imperfecta (OI) is consistently linked to the two loci encoding the $\alpha 1$ (COL1A1) and $\alpha 2$ (COL1A2) subunits of type 1 collagen, the predominant bone collagen. The disease results from a different mutation in each separate family and there are no phenotypical markers which reliably predict whether the disease is linked to COL1Al or COL1A2 in a family. We have performed several prenatal diagnoses based on identification of the segregating allele at the concordant locus in chorionic villus samples, both in families where the linkage can be independently demonstrated and in those where it cannot. In the latter, risk calculations take into account estimates of genetic heterogeneity within the OI population generated by a collaborative study of 38 families (Sykes et al. Am $\mathcal{F}$ Hum Genet, in press). This recommends including a $5 \%$ prior risk that a new family is not linked to either of the collagen 1 loci.
Polymerase chain reaction amplification of dimorphic restriction sites at COL1A1 and COL1A2

R E BAKER, J R LYNCH, L M PRIESTLEY, B C SYKES Collagen Genetics Group, Institute of Molecular Medicine, John Radcliffe Hospital, Oxford.

Type I collagen is the major structural component in bone and skin. Several restriction fragment length dimorphisms are known at the loci for COL1A1 and COL1A2, the genes encoding type I collagen. Use of three dimorphisms at each locus has shown that the dominantly inherited forms of osteogenesis imperfecta are linked to one or other of these loci (Sykes et al. Lancet 1986;ii:69-72). The polymerase chain reaction provides a means of faster analysis of the dimorphisms than conventional Southern blotting. Sequencing of the regions flanking the dimorphic sites has allowed the selection of suitable primers. Amplification of the regions and subsequent digestion with the appropriate restriction enzyme has given faithful duplication of Southern blot results in all six of the sites. Application of this system in prenatal diagnosis offers considerable advantages.

Enhanced chemiluminescence detection of Western blotted proteins LINDA PROUDFOOT, JULIE SIMMONDS, ANGELICA DEVENISH, IAN FELIX Amersham International plc, Life Science Development, Amersham Laboratories, Amersham, Bucks.

Immunodetection with horseradish peroxidase labelled antibodies can be performed efficiently and rapidly with enhanced chemiluminescence (ECL). This method allows for high sensitivity and convenient detection of immobilised specific antigens conjugated directly or indirectly with horseradish peroxidase labelled antibodies. Enhanced chemiluminescence detection offers at least 10 times greater sensitivity over colourimetric detection methods enabling the detection of less than $1 \mathrm{pg}$ specific antigen, with the added advantage of hard copy results on film. We have used this system in Western blots and dot blots to detect various proteins, among them human GC (in collaboration with MRC Human Biochemical Genetics Unit and
Home Office Forensic Science Service), cytoskeletal proteins in rat glial cell lysates, circulating antiheart antibodies after heart transplantation (in collaboration with National Heart and Lung Institute), and 5T4 glycoprotein (in collaboration with Patterson Institute of Cancer Research).

Detection of allele loss in ovarian cancer

B J MILNER*, N E HAITES*, K F KELLY*, M HALL $†$, H KITCHENER $\dagger$, A W JOHNSTON $\ddagger$ *Department of Genetics and Microbiology, University of Aberdeen; tAberdeen Maternity Hospital, Foresterhill, Aberdeen; $\neq W$ ard 3/4, Aberdeen Royal Infirmary, Foresterhill, Aberdeen.

DNA has been analysed from 21 ovarian tumours, of which nine were malignant and five were of borderline malignancy. Using chromosome $17 p$ probes, pYNZ22 and pBHp53, tumour and normal DNA have been compared. Informative results obtained for seven of the malignant tumours showed that five $(71 \%)$ had lost a pYNZ22 allele. In addition, one of these tumours was found to have a deleted $\mathrm{pBHp} 53$ allele, while all the other malignancies examined were uninformative for this probe. None of the benign or borderline tumours was seen to lose $17 p$ alleles at these loci. This has led us to suggest that loss of function of an antioncogene from $17 p$, such as P53, could be involved in the transition from the benign to the more malignant stages of ovarian cancer. One of the five malignancies found to be deleted for pYNZ22 is a familial case, and has been shown to have lost a $6 \mathrm{~kb}$ fragment in comparative 'DNA fingerprinting' studies.

Familial neural tube defects in the west of Scotland, 1976-1986 ELAINE DRAINER, HEATHER M MAY, J L TOLMIE

Duncan Guthrie Institute of Medical Genetics, Royal Hospital for Sick Children, Yorkhill, Glasgow.

Eighty-eight probands with neural tube defect (NTD) and one or more affected sibs were ascertained in the west of Scotland between 1976 and 1986. In 48 sibships there were sufficient clinical, radiological, and patho- 
logical data to classify the NTD according to the site of the lesion. From a total of 102 cases, 21 had anencephaly alone, 40 had anencephaly and spina bifida, 40 had spina bifida alone, and one infant had an occipital meningocele. Classifying lesions above T12 as 'high' and lesions below this vertebral level as 'low', the ratio of high:low lesions was $87: 15$. All cases of low lesions had an affected sib with a high lesion. There was a female excess among cases with high lesions (28M: 59F) and a male preponderance among low lesions (9M:6F). The preponderance of high lesions and the absence of concordance within sibships for the level of the lesion are notable features of this data set from the west of Scotland.

\section{Serum $\alpha$ fetoprotein in fetuses with Down's syndrome in the midtrimester \\ MARY J SELLER \\ Department of Medical and Molecular Genetics, Guy's Hospital, London.}

Maternal serum $\alpha$ fetoprotein (MSAFP) levels tend to be lower than normal in the early midtrimester when the fetus has Down's syndrome (DS). It has been suggested that the reason for this is that DS fetuses produce less AFP than normal fetuses. The serum AFP levels of fetuses with and without DS have been estimated and compared from the 17th to 28th week of pregnancy. In normal fetuses, the serum AFP level declines linearly during this period. Before 20 weeks, DS serum AFP is the same as that of normal fetuses, but after 20 weeks it declines more rapidly than normal. By the end of the second trimester levels are lower than normal. This suggests that the low MSAFP levels used for early midtrimester screening for DS cannot be explained by low AFP levels in the DS fetuses themselves.

\section{Frequency of HLA class II alleles in severe pre-eclamptics compared with normotensive controls C HAYWARD, A GILFILLAN, I McINTOSH, D J H BROCK Human Genetics Unit, University of Edinburgh.}

Severe pre-eclampsia occurs in 4 to $7 \%$ of first pregnancies. It is defined by severe hypertension $(B P>140 / 90)$ with proteinuria ( $>0.25 \mathrm{~g} / \mathrm{l}$ urine). The cause of pre-eclampsia is unknown. However, it has been suggested that over-suppression of the maternal immune response contributes to the disease. Serological studies have reported an increased frequency of HLA-DR4 homozygosity in preeclamptics compared with normotensive subjects. Using the technique of PCR it is possible to identify many more class II alleles than by serotyping. By analysis of the most common DRB, DQA, and DQB alleles, it appears that previous serological observations of class II homozygosity are not genuine, but are a result of the limitations of HLA serology.

A new RFLP within the DMD gene

I D HAGGERTY, J KEEN, A CURTIS, S S BHATTACHARYA

Department of Human Genetics, University of Newcastle upon Tyne.

We have identified an RFLP with $X m n I$ digested DNA samples using the intragenic DMD probe pERT87-8, a subclone of DXS164 (Kunkel et al. Nature 1986;322:73-7). Family studies were carried out to show that the alleles were segregating in a mendelian fashion. The allele frequencies were estimated in a total of 130 chromosomes from an unrelated sample of the British Caucasian population.

$X m n I / p E R T 87-8$

$\begin{array}{lll}\text { Allele } & \text { Size } & \text { Frequency } \\ \text { p } & 8.8 \mathrm{~kb} & 0.65 \\ \mathrm{q} & 9.2 \mathrm{~kb} & 0.35\end{array}$

This provides an additional system useful for carrier detection and prenatal diagnosis of Duchenne and Becker muscular dystrophies.

\section{Experience of the polymerase} chain reaction in the diagnosis of Duchenne and Becker muscular dystrophy: benefits and problems encountered SUZANNE CLARK, SHU C YAU, STEPHEN ABBS, ROLAND G ROBERTS, DAVID R BENTLEY, CHRISTOPHER G MATHEW, MARTIN BOBROW Paediatric Research Unit, Division of Medical and Molecular Genetics, Guy's Hospital, London.

The routine diagnosis of $\mathrm{DMD} / \mathrm{BMD}$ has been greatly facilitated in our laboratory by the introduction of the method of PCR. Both the initial screening of affected boys for deletions and RFLP linkage analysis of family members are routinely performed by PCR. The multiplex deletion screening reactions of Chamberlain et al (1988) and Braggs et al (submitted) have been modified to cover separately the deletion 'hotspots' at the 5 ' and central regions of the dystrophin gene. Our $3^{\prime}$ and $5^{\prime}$ multiplexes independently cover $77 \%$ and $22 \%$ of all deletions, respectively. Analysis of 60 known deletion patients with each of these multiplexes (30 each) gave concordant results between the Southern cDNA data and PCR data. Six intragenic polymorphic loci are currently typed by PCR. Two of these, recently discovered by the method of amplification and chemical mismatch analysis (Roberts et al, 1989, 1990) are located at the extremities of the dystrophin gene. The other four are polymorphisms in the DXS164 (pERT87) locus that have been converted to the method of PCR. We estimate that 80 to $90 \%$ of females will be heterozygous for at least one of these six intragenic loci. Some problems have been identified with the method of PCR, including non-amplification from chromosomes owing to sequence variations within the site of primer hybridisation (Fujimura et al, 1990; Abbs et al, submitted), partial digestion of amplification products, and variations between individual PCR machines. Although this can lead to incorrect typing and misdiagnosis, as long as laboratories are aware of the potential hazards, and suitable controls are rigorously employed, we believe the enormous benefits of the PCR method greatly outweigh the disadvantages that have been encountered.

Analysis of dystrophin gene deletions in Scottish DMD/BMD patients by means of multiplex PCR amplification

A KATAKI, W G LANYON, A COOKE Duncan Guthrie Institute of Medical Genetics, Yorkhill, Glasgow.

Ninety DMD/BMD patients were analysed by multiplex DNA amplification using the primer sets described by Chamberlain et al (Nucleic Acids Res 1988;16:11141-54). The results were compared to those obtained by Southern analysis using dystrophin cDNA probes. In 20 of the patients at least one inconsistency was observed 
between the two methods. A repeat assay using only one of the sets of primers flanking the disputed region yielded results which confirmed those predicted by conventional analysis in the majority of cases. PCR amplification has also been used in a limited number of cases where only degraded DNA was available from dead patients and which had failed to produce detectable signals by Southern analysis. Two of the patients were shown to be positive for the primers used, but no amplification was detected in the others despite the fact that the average molecular weight of the template DNA was adequate.

\section{One hundred Duchenne muscular dystrophy prenatal diagnoses \\ R C MOUNTFORD, R G ELLES, A P READ \\ Department of Medical Genetics, St Mary's Hospital, Manchester.}

Between April 1985 and February 1990 we carried out one hundred prenatal diagnoses for Duchenne muscular dystrophy. Twenty-two percent of the cases presented for fetal sexing only. In all, there were 63 male fetuses of which 49 were studied further. In 20 the family was known to be transmitting a dystrophin gene deletion. The deletion was seen in six of these and 14 were reported as normal. A further two deletions were picked up for the first time in the fetus. Gene tracking with intragenic RFLPs was used to define the risk for 27 male fetuses without a deletion. Forty-eight percent were assigned a low risk. The risks in this category varied considerably, reflecting the wide variety of pedigree structures and carrier risks of the women involved. Strategies for testing before prenatal diagnosis vary depending on whether biopsies are accepted without the laboratory being able to test for informativeness in advance.

\section{Junction fragments and rare polymorphisms in the dystrophin gene \\ R C MOUNTFORD, A P READ \\ Department of Medical Genetics, St Mary's Hospital, Manchester.}

On occasion families transmitting DMD present abnormal sized bands with either cDNA or genomic probes.
We present examples of three such families where interpretation was difficult. The first family transmitted a rare pERT87-15 RFLP initially mistaken for a junction fragment. The second family had a junction fragment which was masked by the normal digest pattern with one enzyme, but was confirmed with an alternative enzyme. Finally, we present a family with conflicting Cf56a deletion patterns with different restriction enzymes.

\section{A PCR based method for the molecular analysis of $\mathrm{DMD} / \mathrm{BMD}$ G S HIGGINS, M G GILES, N L VEAL, K STEVENSON, E $\mathrm{V}$ DAVISON Regional Cytogenetics Unit, Birmingham Maternity Hospital.}

Duchenne/Becker muscular dystrophy is an $\mathrm{X}$ linked disease caused by a mutation in the dystrophin gene which is a large gene (c $2 \mathrm{Mb}$ ) comprising $>70$ exons giving an mRNA transcript of $14 \mathrm{~kb}$. A total of 60 to $70 \%$ of affected subjects exhibit a deletion within the dystrophin gene using cDNA probes. More recently, the polymerase chain reaction has been used to detect deletions. Using nine sets of primers in a single 'multiplex' reaction, $44(58 \%)$ subjects out of a series of 77 showed a deletion using this method. This provides a rapid method for detection of deletions in DMD/BMD and can be used for prenatal diagnosis.

\section{$\Delta$ F508 mutation analysis and}

XV/KM haplotype study in cystic fibrosis patients in Northern Ireland C A GRAHAM*, A J M HILL*, $P$ EARLE†, E M HOEY $†$,

P J MORRISON*, N C NEVIN*

${ }^{*}$ Medical Genetics, Belfast City

Hospital, N Ireland; + School of

Biology and Biochemistry,

QUB, $N$ Ireland.

We have used PCR and polyacrylamide gel electrophoresis to detect the 3 bp deletion mutations ( $\mathrm{F} 5508$ and $\Delta \mathrm{I} 507)$ in the $C F$ trans membrane regulator gene in $102 \mathrm{CF}$ patients and their parents. The frequency of the most common mutation ( $\triangle \mathrm{F} 508)$ was $54.4 \%$ ( 111 of $204 \mathrm{CF}$ chromosomes). Four $(2.0 \%)$ of our patients show the $\Delta \mathrm{I} 507$ deletion $\left(2^{*} \Delta \mathrm{F} 508 / \Delta \mathrm{I} 507,2^{*}\right.$ $\Delta \mathrm{I} 507 /$ other) as detected by heteroduplex analysis. The PCR product was blunt end cloned into M13 and the DNA sequence showed an ATC deletion $(\Delta \mathrm{I} 507)$. The frequency of this mutation in our population is considerably higher than that reported for others. Of the families for which XV/KM haplotypes were available $90 \%$ (55/61) of $\Delta$ F508 chromosomes had haplotype X1K2 and $100 \%(3 / 3)$ of $\Delta \mathrm{I} 507$ chromosomes had haplotype $\mathrm{X} 2 \mathrm{~K} 2$. The X1K2 haplotype only accounted for $15 \%$ of normal parental chromosomes with X2K1 (37\%) being the most common type. This haplotype did not occur on any of the $\Delta F 508$ chromosomes. Of the patients receiving no pancreatic enzyme supplements $89 \%(8 / 9)$ showed no $\Delta \mathrm{F} 508 / \Delta I 507$ deletion mutations, whereas all patients homozygous for these mutations had pancreatic insufficiency. A preliminary blind heterozygote screening study of control subjects detected twice the expected number of CF carriers (13 in 250).

\section{Mutation analysis of the cystic fibrosis gene \\ F E BEARDS, A HARRIS, F A FLINTER, C G MATHEW Paediatric Research Unit, Division of Medical and Molecular Genetics, UMDS, Guy's Hospital, London.}

We have developed a rapid, non-radioactive test for the most common mutation in the cystic fibrosis (CF) gene, ( $\Delta F 508$ (Mathew et al, 1989). Of $172 \mathrm{CF}$ chromosomes tested, 121 $(70.3 \%)$ have a 3 bp deletion within the 50 bp region flanking the $\Delta F 508$ codon. Haplotype analysis of the CF chromosomes (Harris et al, in press) shows $84 \%$ to be type B (allele 1 for pXV2c/TaqI and allele 2 for KM19/ PstI); $81 \cdot 7 \%$ of the type B chromosomes carry the $\Delta \mathrm{F} 508$ deletion. Of 107 chromosomes with the deletion, 105 had the B haplotype; one had the C haplotype (XV2c-2; KM19-1), and one had the D haplotype (XV2c-2; KM19-2). Of the chromosomes without $\Delta \mathrm{F} 508,53 \%$ were haplotype $B$, $15 \%$ D, 13\% A (XV2c-1; KM19-1), and $19 \%$ C. Data comparing the presence of $\Delta \mathrm{F} 508$ with clinical symptoms have shown that of 15 patients with meconium ileus, nine were homozygous for the $\Delta \mathrm{F} 508$ deletion, five were heterozygous, and one did not have the deletion. Analysis of non- $\Delta \mathrm{F} 508 \mathrm{CF}$ chromosomes for 
other recently described mutations resulted in four out of 44 having G551D (3.3\% overall), while none out of 40 have $\mathrm{R} 553 \mathrm{X}$ ( $<0 \cdot 6 \%$ overall).

\section{A method for routinely extracting DNA from buccal cells for cystic fibrosis carrier screening EDWARD MAYALL, CAROLYN WILLIAMS North West Thames Regional Health Authority Regional DNA Laboratory, Department of Biochemistry and Medical Genetics, St Mary's Hospital Medical School, London.}

Buccal cells from the inside of the cheek may be taken from a patient by either washing the mouth with an isotonic solution or by scraping inside the cheek with a wooden spatula. The amount of DNA extracted from cells obtained by these two methods was compared; it was found that about five times more DNA can be extracted from a wash than from a scrape. The procedure for extraction of DNA suitable for amplification by PCR is as follows: DNA is extracted from buccal cells that have been spun down in medium by boiling in $0.05 \mathrm{~mol} / \mathrm{l}$ $\mathrm{NaOH}(100 \mu \mathrm{l}$ for scrapes and $200 \mu \mathrm{l}$ for washes) and neutralising by adding Tris to a concentration of $100 \mathrm{mmol} / \mathrm{l}$; this method was shown to be reliable. It was found that if samples are to be stored for periods longer than one week, the wash medium should be $4 \%$ sucrose as this reduces bacterial growth which can inhibit PCR. In addition it was shown that freezing is the ideal method of storage of DNA extracted from buccal cells as repeated freeze/ thawing did not reduce the quality of DNA sufficiently to prevent amplification.

Frequency of the $\Delta F 508$ deletion and linkage disequilibrium between non- $\Delta$ F508 mutations and closely linked markers A J WALlace, A J IVINSON Department of Medical Genetics, St Mary's Hospital, Manchester.

Of a sample of 158 cystic fibrosis chromosomes from a north-west English population, $75 \cdot 3 \%$ were found to carry the $\Delta \mathrm{F} 508$ deletion and $3.8 \%$ the G551D mutation. No examples of the $\Delta \mathrm{I} 507$ deletion were found. A subset of $109 \mathrm{CF}$ and 108 normal chromosomes were haplotyped for the three closely linked markers, XV2C, KM19, and CS7. Both the $\Delta$ F508 and G551D samples show strong allelic association with the recognised high risk haplotype, XV2C-1, KM19-2, CS7-2. The remaining 17 as yet uncharacterised mutations still show a residual allelic association with the same haplotype, indicating that at least one further mutation shows the same pattern of linkage disequilibrium. This pattern should not be produced by straightforward heterozygote advantage but suggests some factor acting epistatically from the high risk haplotype driving the accumulation of mutations in the CFTR gene.

\section{Direct detection of the major mutations in cystic fibrosis} N L VEAL, G $S$ HIGGINS, E V DAVISON

Regional Cytogenetics Unit, Birmingham Maternity Hospital.

Following the publication of the 'cystic fibrosis' (CF) gene, a number of tests have been developed to detect the $\Delta$ F508 deletion (major CF mutation). The West Midlands population of patients affected with CF have been screened for this 3 base pair deletion using a system based on PCR. Amplified products on $47 / 50$ base pairs were directly visualised on $16 \%$ polyacrylamide gels. In the West Midlands, $76.5 \%$ of CF chromosomes $(n=136)$ have been shown to carry the $\Delta \mathrm{F} 508$ deletion. This test has been used to alter carrier risks in high risk pregnancies and has also been performed for the prenatal diagnosis of CF.

\section{Adult cystic fibrosis patients: what they and their sibs know about cystic fibrosis \\ J M HAYDON, C MCKEOWN, D E STABLEFORTH East Birmingham Hospital, Birmingham.}

An unselected group of 80 cystic fibrosis patients attending an adult clinic, and 42 of their sibs aged over 16 , were approached to assess/investigate the extent of their knowledge of CF, its inheritance, and the prenatal diagnostic test available. Patients were interviewed in the clinic and their sibs at home. Patients were aged 14 to 33 and sibs 16 to 44 . Patients' knowledge of $\mathrm{CF}$ was varied and related to edu- cational achievements. The majority understood the mode of inheritance and were aware of a risk to their children, but accurate knowledge of this risk was poor. The effect of CF patients on the sibs' lives was felt to be minimal. Sibs' knowledge of CF was varied but awareness of carrier status was poor. Understanding of mode of inheritance and risk to children was similar to the CF patients. Both groups had little knowledge of PND tests available. The results of this study may have implications for planning and uptake of carrier testing now that the CF gene has been located.

Attitudes of parents of cystic fibrosis children towards neonatal screening and prenatal diagnosis L N AL-JADER*, M C GOODCHILD $\dagger$, H C RYLEY $\ddagger$, P S HARPER*

*Institute of Medical Genetics, †Department of Child Health (Cystic Fibrosis Unit), $\ddagger$ Department of Medical Microbiology, University Hospital of Wales, Cardiff.

Information on parents' attitude towards neonatal screening for cystic fibrosis (CF) and prenatal diagnosis bye chorion villus biopsy (CVS) has been derived from a detailed questionnaire administered to parents of CF babies diagnosed early following newborn screening (18 babies) and later on account of clinical criteria (11 babies). Screening was by measurement of immunoreactive trypsin (IRT) on Guthrie card blood spots, which was the basis of the Wales/West Midlands IRT Screening Survey, 1985-1989. Families questioned were from Wales. Most parents supported screening: parents of $15 / 18(83 \%)$ screened babies and $10 / 11(91 \%)$ unscreened babies and $15 / 29(52 \%)$ of families would abort a CF fetus after prenatal diagnosis. Neither standard of education nor social class correlated with attitudes to screening or prenatal diagnosis, although these factors were related to the parents' knowledge of CF in general. Several families emphasised the importance of minimal delay between the initial mention of the possibility of CF on IRT testing and confirmation (or otherwise) of the diagnosis. Four mothers acknowledged temporary rejection of their babies during the period of uncertainty or following the procedures of diagnosis. These findings 
have implications for the widespread introduction of neonatal screening for CF and for programmes of prenatal detection associated with $\mathrm{CF}$ carrier screening.

\section{Further evidence for linkage disequilibrium between D4S95 and the gene for Huntington's disease A DODGE, D CRAUFURD, A KHAN, A READ, $R$ HARRIS \\ Department of Medical Genetics, St Mary's Hospital, Manchester.}

The gene for Huntington's disease (HD) has been localised by genetic linkage analysis to the most distal region of chromosome $4 \mathrm{p}$. Physical mapping techniques have identified three groups of markers in this region, and analysis of recombination events in affected families suggests that the HD gene is located close to or within the most distal of these three segments. However, two recent studies have shown non-random association between $H D$ and polymorphisms detected by the probe BS674 (D4S95) which maps to segment II on the physical map and therefore suggests a more proximal location for HD. We report evidence for linkage disequilibrium with this locus in families from north west England. For the BS674/MboI polymorphism, allele 1 was segregating with the abnormal gene on $38 / 39 \mathrm{HD}$ chromosomes but only $117 / 172$ normal chromosomes $\left(\chi^{2}=12 \cdot 60, \mathrm{p}<0.001\right)$. We also detected linkage disequilibrium between $H D$ and the probe BJ56 (D4S127) which is located proximal to but on the same $500 \mathrm{~kb}$ NotI fragment as BS674 $\left(\chi^{2}=5.84, p<0.02\right)$. In common with previous reports, we found no linkage disequilibrium with the BS674/TaqI polymorphism, nor with markers at the loci D4S10 (segment I) and D4S43 (segment II, distal to D4S95). These findings provide further support for a more proximal location of the HD gene.

Two male sib pairs with choanal atresia, cardiac defects, deafness, dysmorphic facies, eye defects and ear anomalies: CCDDEE syndrome

J BURN, C McKEOWN

Division of Human Genetics, University of Newcastle upon Tyne; West Midlands Regional Genetics Service, East Birmingham Hospital, Birmingham.
We report two male sib pairs who presented with the same syndrome of bilateral choanal atresia associated with a spectrum of additional malformations including cardiac defects, deafness, defects of the eyes, eyelids, and external ear, and a characteristic dysmorphic appearance. The occurrence in two male sib pairs raises the possibility of autosomal recessive or $\mathrm{X}$ linked recessive inheritance. This syndrome is distinct from CHARGE association, an important differential diagnosis in view of the familial occurrence and absence of mental retardation.

\section{Complex trigonocephaly: a further five non-chromosomal cases \\ DAVID R FITZPATRICK, JOHN L TOLMIE \\ Duncan Guthrie Institute of \\ Medical Genetics, Royal \\ Hospital for Sick Children, Glasgow.}

Isolated trigonocephaly results from premature fusion of the metopic suture; it usually requires no treatment and has a good cosmetic outcome. However, trigonocephaly occurring with multiple congenital malformations and/or mental retardation has been reported as a consequence of chromosomal imbalance and a miscellaneous group of syndromes (currently 10 in the London Dysmorphology Database). We present clinical data on five cases of trigonocephaly 'plus' who all have normal peripheral blood lymphocyte karyotypes. One child has mental handicap, trigonocephaly, and no other features. Two children have other soft dysmorphisms in addition to trigonocephaly and mental handicap. One child, whose mother has insulin dependent diabetes mellitus, has a complex craniofacial malformation in addition to trigonocephaly. The last child has mental handicap, optic nerve hypoplasia, trigger fingers, and hypogenitalism. All cases have healthy sibs; the disparate clinical features they display confirms the heterogeneous nature of trigonocephaly 'plus'.

Counselling at a distance in the prenatal diagnosis of ectrodactyly SHEILA SIMPSON*, STEVEN R BEAVEN†

*Medical Genetics Laboratories, Department of Molecular and Cell Biology, University Medical
School Buildings, Foresterhill, Aberdeen; †Balfour Hospital, Kirkwall, Orkney.

The patient, a 21 year old primigravida, presented to her general practitioner at 13 weeks' gestation with a request for fetal sexing. She has ectrodactyly of both hands and feet, as do her sister, mother, and grandmother. The patient believed that if the fetus were female, she would have the same hand and foot abnormalities as herself. She did not wish termination of an affected fetus, but wished to prepare herself for the possibility of an affected female. This patient lives at some distance from the Medical Genetics Centre and was not able to attend for further investigation and counselling. A detailed family history was obtained by her general practitioner, and his examination failed to show any other dysmorphic features. Consultation with the Department of Medical Genetics at Aberdeen led to a working diagnosis of autosomal dominant ectrodactyly. Ultrasound examination of the pregnancy at 30 weeks' gestation showed an affected female. The baby was born at term, and ectrodactyly of both hands and feet confirmed. The hand and foot abnormalities in this family caused the patient's grandmother to limit her family to one child, who was an affected female. This woman, the patient's mother, had two therapeutic abortions because of her fear of producing affected females, but had two affected daughters and two normal sons. Counselling by the general practitioner did not alter the patient's belief that all her daughters will be affected by ectrodactyly. Patients vary in their response to genetic risk. Genetic counselling should merely present accurate facts and options to allow the consultands to make their own decision. Important goals in such counselling are not only to prevent disease, but to lessen patients' guilt and anxiety, and to help them cope with genetic disorders. This family illustrates well the value and limitations of genetic counselling.

The genetic aetiology of anembryonic pregnancy

DEBORAH J HENDERSON, PHILLIP R BENNETT, GILLIAN S GAU, SUSAN BLUNT, CHARLES H RODECK, GUDRUN E MOORE

Institute of Obstetrics and Gynaecology, Queen Charlotte's and Chelsea Hospital, RPMS, Goldhawk Road, London. 
Up to $16 \%$ of all clinically recognised pregnancies are anembryonic. The fetus is absent but there is development of the extraembryonic tissues. These pregnancies eventually miscarry between 8 and 14 weeks. The cause of anembryonic pregnancies are unknown. It may be that anembryonic pregnancies are similar to hydatiform mole, another condition where there is no embryo but abnormal development of the extraembryonic tissues. Hydatidiform mole may in some cases lead to choriocarcinoma. Complete hydatidiform mole has only a paternal contribution to its genome, with the usual chromosome complement being $46, \mathrm{XX}$. This research aims to discover the parental origin of the anembryonic trophoblast using Jeffreys minisatellite probes. Thirteen anembryonic sample sets including trophoblast, maternal and paternal blood have been collected and studied. Following analysis with the minisatellite probes, these showed both a maternal and paternal contribution to its genome, showing that this condition does not arise by the same genetic process as hydatidiform mole. However, in two cases four bands could be seen, suggesting that the tissue was tetraploid or a twin pregnancy. To analyse the possibility that chromosomal abnormalities could play a part in anembryonic pregnancies karyotyping studies are being carried out. We are also studying the degree of maternal-paternal immunosimilarity using HLA-D probes. Immunosimilarity has been suggested to be a factor in recurrent spontaneous abortion, and therefore may also be a factor in the development of anembryonic pregnancies. Ten tissue sets have been examined using the HLA-D probes. Of these, four out of 10 of the parents share the haplotype corresponding to w17, with six out of the 10 sets of parents sharing one of the HLA-D haplotypes. On average, only $25 \%$ of normal couples share a HLA-D haplotype.

\section{Why do patients not attend? V A HOWICK, M A PATTON South West Thames Regional Genetics Service, London.}

Attendance at the Genetic Clinic in St George's Hospital, South West Thames Region, was monitored to establish: (1) \% rate of failed appointments; (2) how this compared to other similar specialties; (3) if there was a persistent major cause; (4) if nonattendance could be predicted and prevented. The first three months' pilot study showed that our failure rate of $12 \%$ corresponded with that of the neurology clinic but was higher than that of the Paediatric Diabetic follow up clinic. All clinics were held in the same outpatient department on Monday mornings. For the following 12 months Genetic Clinic non-attenders were contacted, usually by telephone. Some, with a history of non-attendance were visited, and all these subsequently attended clinic. The failure rate over the year was slightly higher, at $14 \%$. The largest category of non-attendance $(27 \%)$ was because of non-receipt of appointment letters. Most of our referrals are from other hospital departments where follow up appointments are given at the clinic. In Genetics, however, appointments are sent out by post and therefore we depend on having addresses regularly updated. Preclinical visiting is not routine in this region.

Total No of appointments

Total No of new patients

Total of failed new appts

Total of failed review appts

Reasons for non-attendance:

Non-receipt of appointment

Domestic problems

$27 \%$

Forgot

Illness

$10 \%$

$10 \%$

Other

$17 \%$

Sixty percent of non-attenders were aged between 20 and 30 years of age.

PKU in south western England and in the south of the German Democratic Republic: genetic heterogeneity in two populations L A TYFIELD*, E KUNERT $†$, M J OSBORN*, P RUTLAND $\ddagger$

*Department of Clinical

Chemistry, Southmead Hospital, Bristol; +Department of

Human Genetics, Karl Marx

University, Leipzig, GDR;

\#Institute of Child Health,

University of London, London.

We have studied the molecular genetics of PKU in two independent European populations, the south west of England and the region of East Germany centred on Leipzig. Haplotype patterns were defined using the cDNA probe PAH247 (Dr Savio Woo, Houston, Texas) and amplified exons were tested for particular mutations with ASO probes. In both populations most mutant alleles were found on haplotypes 1 to 4; however, the frequency of distribution differed in the two groups, haplotype 2 occurring most frequently in the German population and haplotype 3 in the English. The frequency of specific mutations paralleled that of the haplotype patterns, the point mutation in exon 12 being most common in the German group and the splice mutation in exon 12 the most common in the English. In both populations there was some heterogeneity in linkage between haplotype patterns and specific mutations. For example, in only one German family haplotype 1 was associated with the exon 7 mutation and in two English families haplotype 1 carried the point mutation in exon 12. Haplotype 4 alleles carrying the exon 5 mutation was found only in the German population; $63 \%$ of all PKU genes in the English group did not carry any of these four mutations. This study confirms the considerable genetic diversity of PKU both withing and between populations.

\section{MEN2A: the Northern Ireland/ Australian pedigree \\ P J MORRISON*, A E HUGHES*, N C NEVIN*, D R HADDEN†, C F J RUSSELL † \\ ${ }^{*}$ Regional Medical Genetics Centre, Queen's University, Belfast; +Sir George E Clark Metabolic Unit, Royal Victoria Hospital, Belfast; $\neq$ Department of Endocrine Surgery, Royal Victoria Hospital, Belfast.}

The Northern Ireland MEN2A family originally described in 1987 (Hadden et al. Henry Ford Hosp Med $\mathcal{F} 1987 ; 35: 107-9)$ is presented. Four members of the first generation studied have died, three men as a result of metastatic medullary thyroid carcinoma and one woman (the index case) from hypertensive complications during thyroidectomy from an undiagnosed phaeochromocytoma. In this highly penetrant autosomal dominant family, there are eight males and five females affected. Affected members found to have either medullary thyroid carcinoma or phaeochromocytoma or both have been asympto- 
matic. One man, in addition to medullary thyroid carcinoma and phaeochromocytoma, had a parathyroid adenoma. The locus has been localised to the pericentromeric region of chromosome 10 (Nakamura et al. Genomics 1989;5:199-203). Our family is informative using gene probes MCK2, TB10.163, RBP3, and TBQ14.34.

Clinical application of $\mathbf{M} 27 \boldsymbol{\beta}$ as

a linked probe and for carrier

detection by $X$ inactivation studies in Wiskott-Aldrich syndrome

J GOODSHIP, S MALCOLM, J CARTER, Y BOYD

Department of Human Genetics

Newcastle-upon-Tyne; Institute of Child

Health, London; MRC Radiobiology

Unit, Didcot, Oxon.

Wiskott-Aldrich syndrome (IMD2) is an X linked recessive disorder characterised by immunodeficiency, thrombocytopenia, and eczema. Before the use of bone marrow transplantation life expectancy was less than 10 years with intracranial haemorrhage and recurrent infections the main cause of early death, and lymphoreticular malignancy and leukaemia the commonest cause of later deaths. Female carriers of IMD2 are clinically normal and there is no reliable immunological carrier test. However, it was shown by Prchal and colleagues in 1980 that female carriers have non-random use of the $\mathrm{X}$ chromosome in granulocytes, platelets, monocytes, and $\mathrm{B}$ and $\mathrm{T}$ lymphocytes. The disease has been mapped to Xpll and the most likely order of loci is DXS7-(DXS255-TIMP-IMD2)DXS14-centromere. The probe M27B at $D X S 255$ also detects methylation differences between the active and inactive $\mathrm{X}$ chromosome. We have confirmed that this probe identifies non-random use of the $\mathrm{X}$ chromosome in a panel of 18 known non-random samples. We have also shown that it will detect non-random use of the $\mathrm{X}$ chromosome in DNA samples extracted from venous blood of three obligate carriers of IMD2. It can, therefore, be used as a carrier test on venous blood without purification of cells before DNA extraction. As M27 $\beta$ is closely linked to the disease locus we can distinguish which polymorphic allele represents the inactive, that is, affected chromosome, and can use this to establish phase in the absence of living males. It has also enabled us to determine where a new mutation has occurred within one family and to show in another family that the defective gene is running in branches of the pedigree with no affected males. 